\title{
Frequency of Vitamin D Deficiencies in Children Who Living in the South-East of Turkey Region with Plenty of Sunshine
}

\author{
Seçil Conkar ${ }^{1 *}$ and Ebru Afyoncu ${ }^{2}$ \\ ${ }^{1}$ Ege Univercity, Department of Medicine, Department of Pediatric Nephrology, İzmir, Turkey \\ ${ }^{2}$ Diyatbakır Child Hospital Department of Biochemistry, Diyarbakır, Turkey
}

${ }^{*}$ Corresponding author: Secil Conkar, Ege Univercity, Department of Medicine, Department of Pediatric Nephrology, İzmir, Turkey, Tel: 0090 5545390501; E-mail: secilcankar@yahoo.com.tr

Received: August 22, 2017; Accepted: August 30, 2017; Published: September 08, 2017

Citation: Conkar S, Afyoncu E (2017) Frequency of Vitamin D Deficiencies in Children Who Living in the South-East of Turkey Region with Plenty of Sunshine. Ann Clin Lab Res Vol.5:No.3:190.

\section{Abstract}

Objectives: The present study was designed to evaluate the relationship between vitamin D, vitamin B12 and folic acid levels and nutritional status among 24 to 60 months children.

Methods: In this cross-sectional study were performed 116 children at Diyarbakır children hospital. Serum vitamin B12, folic acid and vitamin D levels were measured in all children. Anthropometric indices of weight-for-age and BMI-for-age were used to estimate the children's nutritional status. Z-scores for weight-for-age (WAZ) were derived from Epi info and WHO Anthro Plus softwares. The nutritional status was classified as normal $( \pm 2 S D)$, moderate $(<-2 S D \geq-3 S D)$ and severe $(<-3 S D)$.

Results: The mean serum levels of Vitamin B12, vitamin D, Folic acid and haemoglobinin the study population were $223.1 \pm 8.89 \mathrm{pg} / \mathrm{mL}, 23.5 \pm 8.97 \mathrm{ng} / \mathrm{mL}, 26.5 \pm 18.4 \mathrm{ng} / \mathrm{mL}$ and $11.6 \pm 3.24 \mathrm{~g} / \mathrm{dL}$, respectively. Vitamin $\mathrm{D}$ deficiency, Folate deficiency and vitamin B12 deficiency occurred in $41.4 \%, 3.4 \%$, and $24.1 \%$ of the 24 to 60 months children, respectively. The mean levels of the biochemical indices of vitamin D, vitamin B12 and folic acid levels and haemoglobin levels were not statistically significantly different among different levels of nutritional status normal $(p>0.05)$ and moderate $(p>0.05)$.

Conclusion: The present study shows that, despite the sunny environment, vitamin D deficiency is highly prevalent among of 24 to 60 months children. These findings suggest that much more efficient vitamin $D$ prophylaxis programs should be implemented for risk groups such as infants and 24 to 60 months children.

Keywords: Site-specific recombination; Active partition system; Toxin/anti-toxin system

\section{Introduction}

Dietary deficiencies of micronutrients are an important public health concern in developing countries. The level of adequate intake of micronutrients is of great importance for the wellbeing, proper development, and functioning of the body starting from the fetal life and throughout childhood. They have been implicated to play important roles in immunophysiologic functions [1]. Micronutrient deficiencies can affect all age groups, but preschool children are mostly at risk, especially in the developing countries [2]. In accordance with preceding report, micronutrient deficiency accounts for approximately $7.3 \%$ of the global burden of disease [3]. Although several studies have reported the status of micronutrients among children, little information is available on micronutrients status of 24 to 60 months children [4]. The present study was, designed to evaluate level of micronutrients in Diyarbakir among 24 to 60 months children. Preschool children aged 24 to 60 months have been identified as the most nutritionally vulnerable group in this situation, foods would be difficult to meet the needs to a variety of micronutrients so that these populations would be at high risk suffered from nutritional deficiencies due to a low intake of animal source of foods, especially micronutrients such vitamin $\mathrm{D}$ and folic acid, vitamin B12 which would be most likely to be deficient in children $[5,6]$. There are some evidences that these micronutrients have specific critical roles in children's growth and brain nutrition $[7,8] .25(\mathrm{OH}) \mathrm{D}$ is the major circulating form of vitamin $D$, and its levels are the best available indicator of total body vitamin D status. Serum $25(\mathrm{OH})$ D levels reflect endogenously synthesized vitamin $D$ and that obtained from the diet. Normal reference values depend on factors such as sunlight exposure, season, latitude, skin pigmentation, age, dietary vitamin $D$ intake and the assay method used [9]. The primary objective of this survey was to assess the growth status, the prevalence of anemia and the other micronutrient deficiencies (vitamin D and vitamin B12 and folic acid) in the children aged from 24 to 60 months living in the south-east areas and to provide the basic evidence for making strategy on nutrition intervention for such areas. 


\section{Materials and Methods}

The study was conducted during October-November 2015 in Diyarbakir ( $52^{\circ}$ East latitude). A population based short study was designed. This study was conducted in compliance with the regulation of patient rights and ethical rules. Local Ethics Committee approval was received accordance with the ethical standards of 2013 Declaration of Helsinki. A total of 116 children from Diyarbakır sample size consisted of healthy volunteers aged 24 to 60 months. These patients visited the hospitals for routine check-ups and were picked randomly from in and around Diyarbakır. All participants were of middle socioeconomic background. The exclusion criteria were: history of renal, haematologic, gastrointestinal or metabolic disease (leukaemia, polycythaemia, hypereosinophilia, cystic fibrosis, hepatitis, cirrhosis, cancer), gastrointestinal surgery, malnutrition, growth retardation, malabsorption, or prematurity; taking drugs containing vitamin B12; infants being formula-fed; usage of any anti-epileptic drug; history of parasitic infections; and emigrants of other races.

All children were sampled for evaluating vitamin $D$, vitamin B12 and folic acid status.

Anthropometric measurements; body weight and height measurements of the children were obtained carefully by the same experienced staff. Body mass index (BMI) was calculated by the formula: $B M I=k g / m 2$. The $B M I$ measurements were calculated based on WHO growth for Turkish children [10].

Blood sampling and biochemical analyses; complete blood counts and serum vitamin B12, folic acid and vitamin D levels were measured in all children. All tests were performed in Diyarbakır Child's Hospital of Clinical Laboratory using their standard protocols. A fasting blood sample (3 to $5 \mathrm{~mL}$ ) was drawn from an antecubital vein puncture by local hospital staff. The blood specimens were analyzed. Hemoglobin concentration in whole blood was assayed using the Mindray $\mathrm{BC} 6800$. Anemia was defined as $\mathrm{Hb}<11 \mathrm{~g} / \mathrm{dL}$ on the basis of World Health Organization (WHO) criteria [11].

Serum 25-OH-D3, vitamin B12 and folic acid were determined by using Unicel DxI 800 Access Immunoassay
System commercial radioimmunoassay kits. The Biochemistry Diyarbakır Child's Hospital of Clinical Laboratory of measured the levels of vitamin B12 with original Beckman kits (Beckman Coulter, CA, USA) by the chemiluminescent method on UniCel DXI 800 Access immunoassay device (Beckman Coulter, CA, USA). The recommended reference interval by the manufacturer was 2000 to $900 \mathrm{pg} / \mathrm{mL}$. The cut off points used for serum folic acid were $<3 \mathrm{ng} / \mathrm{mL}$ for deficiency, 3 to $6 \mathrm{ng} / \mathrm{mL}$ for low levels, and $>6 \mathrm{ng} / \mathrm{mL}$ for normal values. Vitamin B12 deficiency was defined as serum concentration below 200 $\mathrm{pg} / \mathrm{mL}$. The following vitamin $\mathrm{D}$ cut off values were used to define the respective micronutrient deficiency states: vitamin $D$ deficiency $<10 \mathrm{ng} / \mathrm{mL}$, vitamin $\mathrm{D}$ insufficiency $>10$ to $\leq 20$ $\mathrm{ng} / \mathrm{mL}[12]$.

Descriptive statistics are outlined for all variables assessed. Means and SD were calculated for all normally distributed continuous measures including age, vitamin D, vitamin B12, folic acid and haemoglobinin level. Data were analyzed with SPSS 20. The independent samples $T$ test was used for comparing variance. Pearson correlation was used for comparing means. The significance level was set at $p<0.05$.

\section{Results}

The study sample consisted of 116 children between 24 to 60 months of age. There were almost equal proportions of males $(56.9 \%, n=66)$ and females $(43.1 \%, n=50)$. There was no significant difference in the mean age between genders. The mean serum levels of vitamin B12, vitamin D, folic acid and haemoglobinin the study population were $283.6 \pm 139.3$ $\mathrm{pg} / \mathrm{mL}, 16.5 \pm 22.2 \mathrm{ng} / \mathrm{mL}, 12.8 \pm 6.2 \mathrm{ng} / \mathrm{mL}$ and $11.8 \pm 3.2$ $\mathrm{g} / \mathrm{dL}$, respectively. Vitamin $\mathrm{D}$ deficiency was the most prevalent micronutrient deficiency among the children (41.4\%), vitamin D insufficiency was prevalent micronutrient deficiency among the children $40.5 \%$ and $41.4 \%$ of the children had vitamin $D$ deficiency the prevalence of anaemia was marginally (19\%). 28 children (24.1\%) had vitamin B12 deficiency. 4 children $(3,4 \%)$ had folic acid deficiency. The levels of serum micronutrient status deficiency prevalence of Vitamin B12 and vitamin D of children were shown in Table 1.

Table 1 Biochemical indices of micronutrient status and deficiency prevalence of the children in the study.

\begin{tabular}{|c|c|c|}
\hline Analytes & Mean \pm SD & Deficiency n (\%) \\
\hline Vitamin D (ng/mL) & $23.5 \pm 8.97$ & $48(41,4)$ \\
\hline Vitamin B12 (pg/mL) & $223.1 \pm 8.89$ & $28(24,1)$ \\
\hline Haemoglobin (g/dL) & $11.6 \pm 3.24$ & $22(19,1)$ \\
\hline Folic acid (ng/mL) & $26.5 \pm 18.4$ & $4(3,4)$ \\
\hline
\end{tabular}

\section{Discussion}

The results of this study show that nutritional vitamin D deficiency seems to be an important health problem among the children who are admitted to our hospital. Nearly half of the children have vitamin $D$ deficiency. May be this study is just the tip of the iceberg and we need more comprehensive studies with more subjects. The deficiency of vitamin $D$ is an important problem both in the rural areas and in the EastSoutheast regions of our country. It is reported that air 
pollution can also trigger the deficiency of vitamin $D$ in the cities. According to recent studies air pollution has a devastating impact on ultraviolet effect of the sun. Because of this impact, even the children and adults living in sunny regions may develop the deficiency of vitamin D [13].

In Turkey, it was reported that maternal vitamin D deficiency, prolonged non supplemented breastfeeding, and limited sunlight exposure have been playing major roles in the rising incidence of vitamin D deficiency [14-16]. It was found that $89 \%$ of cases who had veiled mothers were exposed to limited sunlight during pregnancy.

Vitamin B12 deficiency has been reported much more common than folate deficiency in underdeveloped countries. Vitamin B12 deficiency constitutes $74 \%$ of megaloblastic anaemia in India where folate deficiency is responsible in $8.4 \%$ of the patients [17]. In 219 Mexican children aged 18 to 36 months prevalence of deficient and low plasma vitamin B12 concentrations were found to be $8 \%$ and $33 \%$, respectively, without any folate deficiency [18]. On the other hand, GarciaCasal et al. [19] investigated prevalence of folic acid and vitamin B12 deficiencies in infants, children, adolescents, and pregnant women in Venezuela and found that folate deficiency was higher than $30 \%$ for all groups studied, reaching $81.79 \%$ in adolescents, and vitamin B12 deficiency was $11.4 \%$ in samples collected. The number of studies examining vitamin B12, folate vitamin deficiencies in children in Turkey is limited. In one study performed on children between the ages of 7 and 17 in three regions of Turkey, it was found that the prevalence of folic acid deficiency was $1.6 \%$ and while the prevalence of Vitamin B12 was 1.3\% in the Central Anatolia region [20]. In a study performed in Southeast Anatolia region, it was determined that the prevalence of Vitamin B12 deficiency was $10.8 \%$, but no folic acid deficiency was found in children [21]. Additionally, in a province of Southeast Anatolia region, the prevalence of deficiencies of folic acid and Vitamin B12 were found to be 21.8 and $2.2 \%$, respectively between the ages of 12 and 22 [22]. According to the results of our study, the prevalence of folic acid deficiency was determined $1.1 \%$ in girls that is similar to the results found in the study performed in Central Anatolia region. The prevalence of Vitamin B12 deficiency was determined to be $3.8 \%$ in boys and $3.3 \%$ in girls, which was higher than the prevalence reported in other studies, except for the study performed in Southeast Anatolia region. In our study vitamin B12 deficiency $24.1 \%$ and folic acid deficiency $3.4 \%$ were found.

\section{Conclusion}

In conclusion, although Turkey is located in a sunny region; vitamin D deficiency is still a serious health problem in children and infants, especially among the low socioeconomic status of Turkish population. Vitamin D deficiency is an important health problem among our patients. This shows the importance of the awareness of vitamin D deficiency in our population. Screening and early treatment for vitamin D deficiency will prevent development of serious problems in children. This study showed that, despite a sunny environment, vitamin D deficiency and insufficiency are highly prevalent among 24 to
60 months children. This is generally due to the life style and nutritional status. These findings suggest that much more effective vitamin $D$ prophylaxis programs should be implemented for infants as well as for 24 to 60 months children.

\section{Acknowledgements}

We thank all paediatrician who work our hospital, for great support this study. Authors would like to thank the Ethical Committee for granting approval, and the technical staff for their skilled assistance.

\section{References}

1. Failla ML (2003) Trace elements and host defense: Recent advances and continuing challenges. J Nutr 133: 1443-1447.

2. Hincal $F$ (2007) Trace elements in growth: lodine and selenium status of Turkish children. J of Trace Elem in Med and Bio 21: 40-43.

3. Bárány E, Bergdahl IA, Bratteby LE, Lundh T, Samuelson G, et al. (2002) Trace element levels in whole blood and serum from Swedish adolescents. Sci Total Environ 286: 129-141.

4. Rodríguez-Morán M, Guerrero-Romero F (2008) Serum magnesium and C-reactive protein levels. Arch Dis Child 93: 676-680.

5. Graham SM, Arvela OM, Wise GA (1992) Long-term neurologic consequences of nutritional vitamin B12 deficiency in infants. J Pediatr 121: 710-714.

6. Zhao XF, Yin SA, Zhao LY, Fu P, Zhang J, et al. (2010) The nutritional status among children under 60 months year-old after one year of the Earthquake in Wenchuan. Chin J Prev Med 44: 691-695.

7. Rosales FJ, Zeisel SH (2008) Perspectives from the symposium, the role of nutrition in infant and toddler brain and behavioral development. Nutr Neurosci 11: 135-143.

8. Benton D (2010) The influence of dietary status on the cognitive performance of children. Mol Nutr Food Res 54: 457-470.

9. Hollis BW (2010) Assessment and interpretation of circulating 25- hydroxyvitamin $\mathrm{D}$ and 1, 25-dihydroxyvitamin $\mathrm{d}$ in the clinical environment. Endocrinol Metab Clin North 39: 271-286.

10. Neyzi O, Günöz H, Furman A, Bundak R, Gökçay G, et al. (2008) Body weight, height, head circumference and body mass index reference values. Child Health and Disease Review 51: 1-14

11. Benoist B, McLean E, Egli I, Cogswell M (2008) Worldwide prevalence of anemia 1993-2005. Geneva, Switzerland: World Health Organization.

12. Braegger C, Campoy C, Colomb V, Decsi T, Domellof $M$, et al. (2013) Vitamin D in the healthy European paediatric population. J Pediatr Gastroenterol Nutr 56: 692-701.

13. Agarwal KS, Mughal MZ, Upadhyay P, Berry JL, Mawer EB, et al. (2002) The impact of atmospheric pollution on vitamin $D$ status of infants and toddlers in Delhi, India. Arch Dis Child 87: 111-113.

14. Alagöl F, Shihadeh $\mathrm{Y}$, Boztepe $\mathrm{H}$, Tanakol R, Yarman $\mathrm{S}$, et al. (2000) Sunlight exposure and vitamin D deficiency in Turkish women. J Endocrinol Invest 23: 173-177. 
15. Andiran N, Yordam N, Ozön (2002) A Risk factors for vitamin D deficiency in breast-fed newborns and their mothers. Nutrition 18: $47-50$

16. Hatun S, Ozkan B, Orbak Z, Doneray H, Cizmecioglu F, et al. (2005) Vitamin D deficiency in early infancy. J Nutr 135: 279-282

17. Chandra J, Jain V, Narayan S, Sharma S, Singh V, et al. (2002) Folate and cobalamin deficiency in megaloblastic anemia in children. Indian Pediatr 39: 453-457.

18. Allen LH, Rosado JL, Casterline JE, Martinez $\mathrm{H}$, Lopez $\mathrm{P}$, et al. (1995) Vitamin B12 deficiency and malabsorption are highly prevalent in rural Mexican communities. Am J Clin Nutr 62: 1013-1019.

19. Garcia-Casal MN, Osorio C, Landaeta M, Leets I, Matus P, et al. (2005) Prevalence of folic acid and vitamin B12 deficiencies in infants, children, adolescents and pregnant women in Venezuela. Eur J Clin Nutr 59: 1064-1070.

20. Açkurt F, Wetherilt H, Hacıbekiroğlu M (1995) Biochemical assessment of nutritional status in pre and postnatal Turkish women and outcome of pregnancy. Eur J Clin Nutr 49: 613-622.

21. Koçiye, Koçyiğit A, Ulukanlıgil M, Demir N (2005) The frequency of vitamin B12 and folic acid deficiency in children 9-12 years of age in the Sanliurfa region and their relation with intestinal helminths. J Child Health Dis 48: 308-315.

22. Öncel K, Özbek MN, Onur H, Söker M, Ceylan (2006) A B12 vitamin and folat prevelance of children and adolescents in Diyarbakır. Dicle Med J 33: 163-169. 